This item was submitted to Loughborough's Research Repository by the author.

Items in Figshare are protected by copyright, with all rights reserved, unless otherwise indicated.

\title{
Aluminium-doped zinc oxide deposited by ultrasonic spray pyrolysis for thin film solar cell applications
}

\section{PLEASE CITE THE PUBLISHED VERSION}

http://dx.doi.org/10.1109/PVSC.2014.6924920

\section{PUBLISHER}

(C) IEEE

\section{VERSION}

SMUR (Submitted Manuscript Under Review)

\section{PUBLISHER STATEMENT}

This work is made available according to the conditions of the Creative Commons Attribution-NonCommercialNoDerivatives 4.0 International (CC BY-NC-ND 4.0) licence. Full details of this licence are available at: https://creativecommons.org/licenses/by-nc-nd/4.0/.

\section{LICENCE}

CC BY-NC-ND 4.0

\section{REPOSITORY RECORD}

Arnou, Panagiota, Jake W. Bowers, and Michael Walls. 2019. "Aluminium-doped Zinc Oxide Deposited by Ultrasonic Spray Pyrolysis for Thin Film Solar Cell Applications”. figshare. https://hdl.handle.net/2134/15677. 


\title{
Aluminium-doped zinc oxide deposited by ultrasonic spray pyrolysis for thin film solar cell applications
}

\author{
Panagiota Arnou, Jake W. Bowers and John M. Walls \\ CREST (Centre for Renewable Energy Systems Technology), School of Electronic, Electrical and Systems \\ Engineering, Loughborough University, Leicestershire, LE11 3TU, UK
}

\begin{abstract}
Aluminum-doped zinc oxide (AZO) thin films were deposited on glass substrates by ultrasonic spray pyrolysis, from metal salt precursors. The electrical and optical properties were investigated as a function of the deposition parameters and the optimum conditions were defined. The thin films exhibit $\sim 80 \%$ transparency and a resistivity in the order of $2 \times 10^{-2} \Omega \mathrm{cm}$. The electrical properties can be improved further with post-deposition annealing in vacuum, or with increase in thickness which causes insignificant transmission losses. AZO nanoparticles can be used as a seed layer and affect the optical properties of the material. The optimized process results in good quality AZO films for their application as the transparent conductive oxide (TCO) layer in thin film solar cells.
\end{abstract}

Index Terms - aluminum doped zinc oxide, low cost, photovoltaic cells, solution processing, spray pyrolysis, thin film, transparent conducting oxide

\section{INTRODUCTION}

Thin film solar cells based on chalcogenide semiconductors such as CdTe and CIGS, are a promising alternative to crystalline silicon (c-Si) devices, due to lower material utilization which results in cost savings [1]. However, the manufacturing cost of thin film solar cells needs to be reduced further to be more competitive with c-Si. Conventionally, thin films of semiconductors are deposited using vacuum-based techniques, such as magnetron sputtering or evaporation. These vacuum deposition systems require high capital investment and the avoidance of these expensive techniques could further reduce the manufacturing costs of solar cells.

Ultrasonic spray pyrolysis (USP) is a low cost, atmospheric deposition technique and it is a viable alternative process to vacuum based systems. As a solution-based method, it offers the potential of adjusting easily the precursor solution and deposition parameters, depending on the required material properties. USP is material-efficient and large-area scalable and it can be applied to the thin film solar cell fabrication, for the deposition of various layers including transparent conductive oxides (TCO), absorbers, or buffer layers.

TCO films are used in an increasing number of optoelectronic devices, such as displays and smartphones, as well as solar cells. At present, the most commonly used TCO is tin-doped indium oxide (ITO), as it offers a combination of high transparency and a high electrical conductivity. However, indium is a rare element and as a result, there is increased interest in alternative TCO materials [2]. Zinc oxide $(\mathrm{ZnO})$ is an alternative metal oxide and it is highly investigated because of its non-toxicity, high abundance and lower material cost. Various extrinsic dopants have been used for zinc oxide, such as gallium, aluminum and boron. Aluminum is one of the most commonly used dopants, resulting in high quality optoelectronic properties for TCO applications [3]. Aside from these excellent characteristics, aluminum-doped zinc oxide (AZO) can be easily texturized, which is beneficial for some thin film solar cell applications, by enhancing light scattering and extending the optical paths of light in the device [4].

AZO is conventionally deposited by RF sputtering using high purity $\mathrm{ZnO}: \mathrm{Al}_{2} \mathrm{O}_{3}$ targets, but it can also be deposited by a range of deposition techniques, such as MOCVD, sol-gel or spray pyrolysis [3].

Despite the fact that AZO is a cheaper alternative to ITO, the true low cost potential of AZO as a TCO material for solar cells can only be realized when it is combined with a low cost deposition method, such as spray pyrolysis. Consequently, the aim of this work is to deposit high quality AZO films by USP for their use in thin film solar cells.

AZO thin films were deposited using USP, with varying deposition parameters. The process parameters investigated included the type of the precursor salts, solvent type, solution concentration, solution flow rate, substrate temperature, atomization power and carrier gas flow. Each process parameter affects a combination of material properties, such as the opto-electronic properties, or the crystalline quality. The optimized parameters result in material with sufficiently good quality for implementation in thin film solar cells.

\section{EXPERIMENTAL}

The ultrasonic spray system was placed in a self-contained enclosure, equipped with air extraction. A simplified diagram of the spray system is shown in Fig.1. The system consists of the spray nozzle, the precursor solution, a syringe pump for the liquid delivery, an ultrasonic generator and a substrate heater with a temperature controller. The heater is fixed on a table that is moved on the $\mathrm{x}$ axis, while the nozzle is moved on the $\mathrm{y}$ axis, to cover the entire area of the substrate. The $x-y$ movement is controlled by using a stepper motor driver. The solution is first atomized and the formed droplets are transported to the substrate, which is placed on a heater at a controlled temperature. Nitrogen is used as the carrier gas, to 
transport the droplets directly onto the substrate. The ultrasonic nozzle used in this work was purchased from Sonotek (NY, USA) and has an operating frequency of $120 \mathrm{kHz}$.

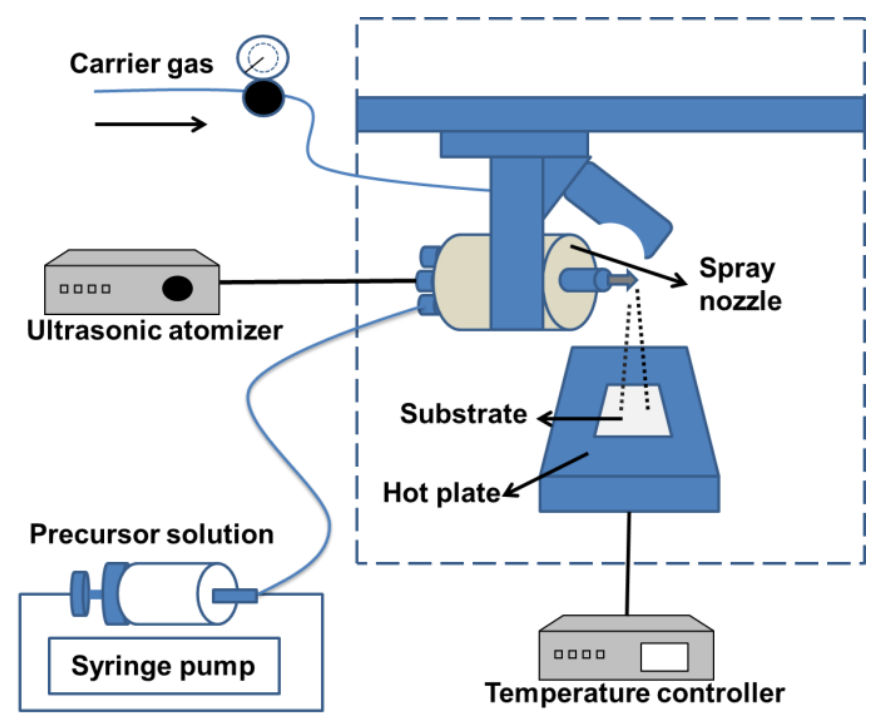

Fig.1. Schematic diagram of the spray setup with the main components.

Solutions of metal salts, aluminum chloride and zinc acetate, were used as the precursors for AZO deposition. Both hydrated and anhydrous compounds were investigated, dissolved in methanol, water or a mixture of the two, with acetic acid as a stabilizing agent [5]. The concentration varied from 0.05 to $0.2 \mathrm{M}$, to obtain the optimum deposition rate and material quality. Also, the doping ratio was varied from 0 (intrinsic material) to $8 \%$, by altering the atomic percent of aluminum relative to zinc.

The material was deposited on clean $5 \mathrm{~cm} \times 5 \mathrm{~cm}$ soda lime glass substrates with $1 \mathrm{~mm}$ thickness. The glass substrates were cleaned using a simplified "RCA Standard Clean" process, which is a wet chemical treatment, conventionally used for cleaning wafers in industry. The RCA process involves the immersion of the substrates in an alkaline mixture (water, hydrogen peroxide and ammonium hydroxide) and then in an acidic mixture (water, hydrogen peroxide and hydrochloric acid) in order to remove organic and inorganic contaminants from the surface [6]. Most of the substrates were cleaned using the RCA process, unless otherwise stated. In some cases, a plasma treatment was incorporated in the cleaning process. The AZO was deposited on clean bare glass, or on a glass substrate coated with AZO nanoparticles, serving as a seed layer.

A large number of process parameters for the spraying conditions were optimized in parallel, in order to obtain good electronic and optical properties. The atomization power and the flow rate of the precursor solution and the carrier gas were varied to obtain a fine mist of droplets. The carrier gas flow rate varied from 5 to 10 liters per minute. Additional parameters, such as the distance between the nozzle and the heater and the deposition temperature were also optimized. Even though the optimization was based on as-deposited samples, a post-deposition annealing step in vacuum was used for some of the samples, with argon or with argon/hydrogen flow. For the application of a seed layer, AZO nanoparticles were spin coated on glass substrates, followed by a short drying step. Such a procedure has been used in a similar way previously, for an aqueous solution deposition approach for $\mathrm{ZnO}$ [7]. The AZO nanoparticles used here were synthetized by detonation of an emulsion containing $\mathrm{Zn}$ and $\mathrm{Al}$ metal precursors [8]. The AZO nanoparticles were supplied by Innovnano SA (Portugal).

The surface morphology was analyzed using a Carl Zeiss 1530 VP Field Emission Gun Scanning Electron Microscope. The grain size from the SEM images was measured offline using AxioVision software (release 4.9.1, Zeiss). A D2 phaser XRD by Bruker was used for the X-ray diffraction analysis. Electro-optical characterization has been carried out on asdeposited and annealed AZO films using UV-Vis-NIR spectrophotometry, four point probe and Hall Effect measurements. For the plasma cleaning, a Glen100-P AE Advanced Energy plasma treatment reactor was used, with $20 \mathrm{sccm} \mathrm{O} \mathrm{O}_{2} / 30 \mathrm{sccm}$ Ar plasma for $5 \mathrm{~min}$ [9].

\section{RESULTS}

\section{A. Electrical Properties}

The optimization process was focused on the electrical properties of the samples, as these change dramatically by altering each deposition parameter. On the contrary, most of the deposition parameters do not materially affect the optical properties in the visible, provided that the thickness, the nature of the substrate and the solvent used are the same.

Initially, a sequence of depositions was carried out using arbitrarily defined process parameters, in order to obtain a practicable range for each parameter. Then, each parameter was varied, while keeping the remaining parameters constant, in order to analyse the effect on the film quality.

For the optimization based on the sheet resistance values, a four-point probe was used. Hall effect measurements were also carried out to determine mobility, carrier concentration and resistivity. An example of the optimization process for one of the parameters is shown in Fig. 2. For the depositions, the same volume of solution was used to deposit similar thicknesses of $\sim 250-300 \mathrm{~nm}$. This thickness was used to speed up and simplify the optimisation process. However, thicker films show improved electrical properties due to the higher carrier concentration and the increased grain growth, which result in improved material quality. The following section 
describes the optimization of some of the deposition parameters.

Atomization power: A narrow range of input power (1.3$1.4 \mathrm{~W})$ to the spray head is ideal for the formation of a fine, low viscosity mist. The atomization of the drops is inefficient at lower power, while higher power leads to droplet cavitation within the nozzle. The partly atomized drops (low power input) and the cavitation bubbles (excessive power input) can both result in poor surface quality and deterioration in the film electrical properties.

Doping level: The optimum doping ratio for this process was found to be $2 \%$. Although the conductivity is increased by increasing the doping, there is a limit on the doping level, as excess doping leads to saturation in the crystal grains and grain boundaries. Films with excessive doping levels tend to have an increased ionized impurity scattering, which limits the carrier transport in the material [10].

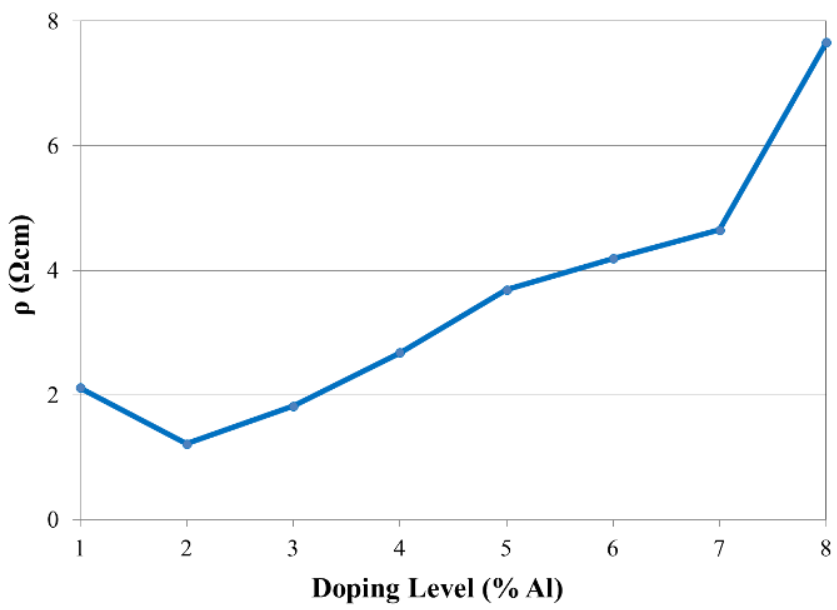

Fig.2. Example of the optimization based on the resistivity values. The samples have a comparable thickness of $250-300 \mathrm{~nm}$.

Carrier Gas Flow: High flow rates of carrier gas result in the cooling of the heated substrate and thus the incomplete pyrolysis of the precursors. Conversely, low flow rates do not deliver the droplets efficiently to the substrate surface and as a result, the deposition rate is reduced. An optimum rate of 6 litres per minute (LPM) was determined.

Precursor flow rate: High flow rates result in bigger droplets and therefore thicker films and lower sheet resistance. Very high flow rates however, result to incomplete atomization and a low quality material, with the non-atomized droplets forming separate domains on the surface and causing inhibited carrier transport.

Temperature: High deposition temperatures compensate the cooling effect from the carrier gas and result in more conductive films. However, at very high temperatures $\left(>500^{\circ} \mathrm{C}\right)$ there is rapid solvent evaporation inside the spray head which causes the nozzle to be clogged.
Annealing: The sheet resistance of the films is significantly decreased by annealing due to improved crystal quality. By vacuum annealing, some adsorbed oxygen is removed from the as-deposited film, present due to the deposition occurring in an oxygen containing atmosphere [11] and therefore annealing increases the conductivity of the films. This improvement is more pronounced for annealing in an hydrogen ambient, as hydrogen can reduce the excess oxygen species.

Other parameters: The effect of the type of the precursor, the solvent mixture and different deposition temperatures was also investigated. The addition of a small amount of water $(5 \% \mathrm{v} / \mathrm{v})$ for the same precursor types and concentrations, results in much more resistive films. Water has a higher surface tension than methanol, which results in bigger droplets and poor film quality [12]. Additionally, it can be related to the presence of hydrated zinc species and the presence of excess amount of oxygen in the film.

The use of anhydrous compounds compared to hydrated compounds dissolved in the same solvent mixture, results in more resistive films at low deposition temperatures. However, the sheet resistance values for hydrated and anhydrous compounds are comparable at higher deposition temperatures or after annealing in a reducing atmosphere. The improvement in conductivity with annealing is more pronounced at low deposition temperatures, in which case there is a more obvious change in the crystal quality. The effects of the annealing treatment, type of precursor, solvent combination and deposition temperature are shown in Fig. 3. A constant volume of precursor $(20.4 \mathrm{ml})$ was used for the depositions in order to deposit a comparable thickness.

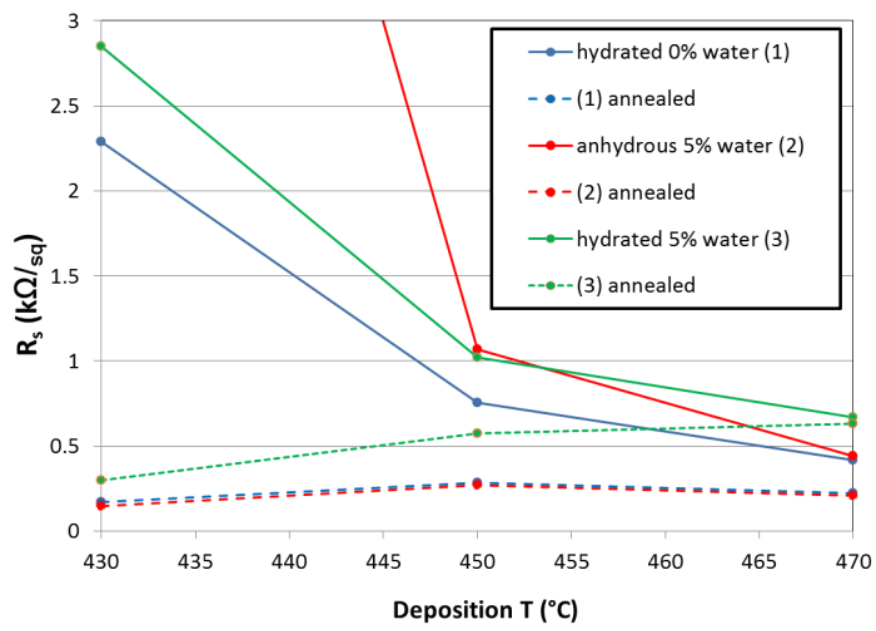

Fig.3. The effects of the type of precursor, solvent and deposition temperature on the sheet resistance. Solid lines: as deposited samples, dotted lines: annealed samples.

\section{B. Optical Properties}

The optical properties and specifically the transmittance did not vary significantly with the variation of the deposition 
parameters but were indirectly associated with the parameters that affect the thickness of the samples. Therefore, the optimization process was focused on the electrical properties. However, some additional adjustments of the AZO deposition procedure were found to affect the optical properties of the material. In particular, it was found that the use of nanoparticles as a seed layer and the incorporation of a plasma treatment step for substrate cleaning, had a dramatic effect on the optical properties.

AZO nanoparticles were deposited as a seed layer for sprayed AZO, using spin coating. The use of a seed layer was proven to be essential for layer nucleation using an aqueous solution deposition approach, presented in a recent study [7]. Intrinsic zinc oxide was sputtered as a seed layer for AZO, which when was incorporated in a CIGS solar cell, where a device efficiency of $14.7 \%$ was achieved [7]. In this study, we have used spin coating for the preparation of a seed layer to eliminate the vacuum processing step. The implementation of nanoparticles as a seed layer results in increased transmission, compared to a sample deposited directly on glass, with a comparable thickness. Also, the absence of interference fringes is an indication of a rough surface [13]. Textured TCOs can be beneficial in certain thin film applications, such as thin CIGS solar cells [4] or amorphous silicon solar cells [14].

For some depositions, a plasma treatment was performed for the substrate cleaning, prior to the TCO deposition. Similarly with the seeded AZO sample, the transmittance is higher than expected for a conventionally cleaned substrate. Also, the interference fringes are suppressed to some extent (but are still evident) which indicates that the surface is rough.

Fig. 4 shows the transmittance and reflectance spectra from a sample deposited on bare glass (a), a sample deposited on a seed layer comprised of nanoparticles (b) and a sample deposited on a substrate which was plasma treated (c). All three samples were deposited using the optimum parameters, that were defined according to the electrical properties, as analyzed in section III(A). The effect of each treatment on the optical properties of AZO, allows us to adjust the transmission, surface roughness and mobility by controlling the pretreatment of the substrate; either by incorporating a seed layer for the layer nucleation, or by plasma treatment. This requires more investigation and will be carried out in future work.

All the sprayed films have high transmission in the visible wavelength range, with an average transmission of $78 \%$ and $82 \%$ for the $1.8 \mu \mathrm{m}$ and $1.2 \mu \mathrm{m}$ thick films, respectively. The transmittance can be improved further by altering the pretreatment of the substrate.

The optical band gap was determined using Tauc plots, by taking into account the transmission and reflection spectra. The band gap of the material is estimated to be $3.32 \mathrm{eV}$, which corresponds to the band gap of zinc oxide [15].

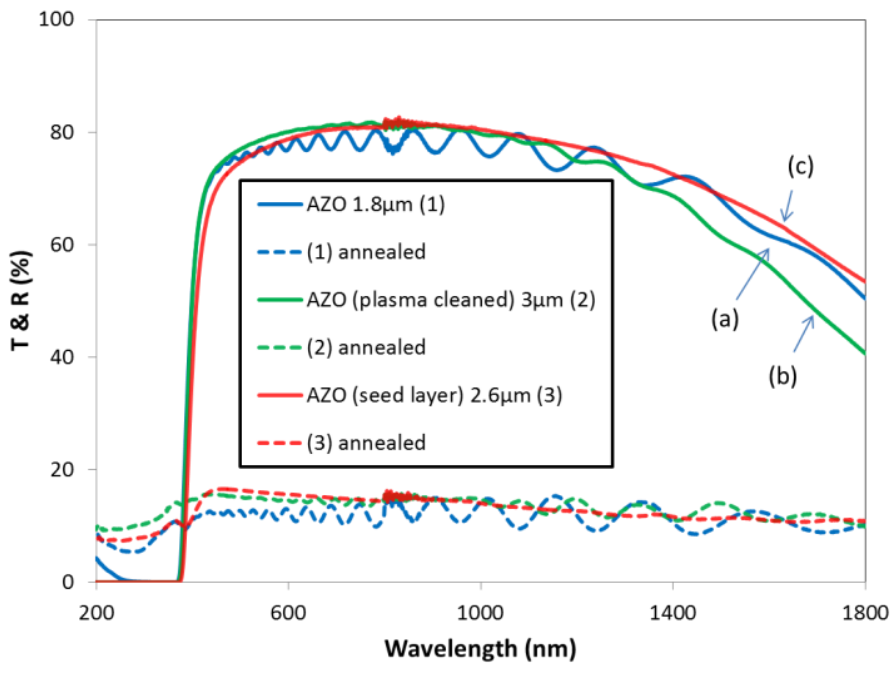

Fig.4. Transmission and reflection spectra of three films; (a): AZO on bare glass, (b): AZO grown on a seed layer, (c): AZO on plasma cleaned sample.

\section{Structural Properties}

The XRD pattern of an as-deposited sample on glass is shown in Figure 5. This pattern verifies the hexagonal structure of the zinc oxide, according to the ICDD reference pattern (00-036-1451).

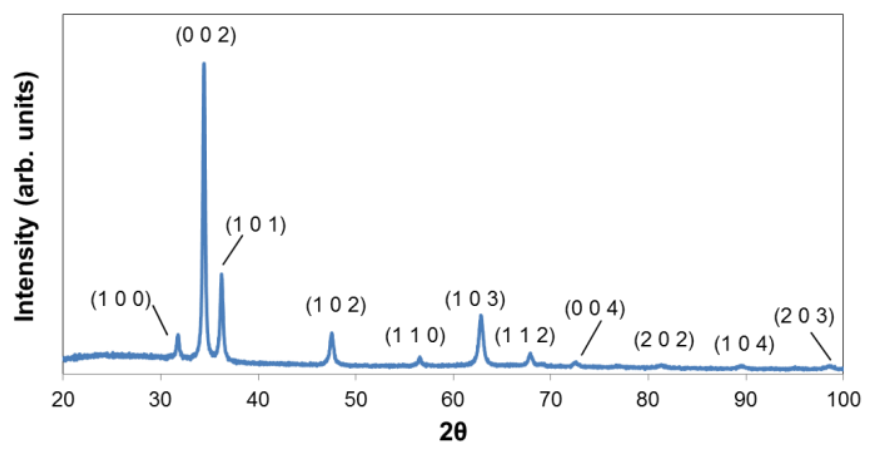

Fig.5. XRD pattern of AZO, deposited on glass. The peaks correspond to the hexagonal structured zinc oxide (ICDD 00-0361451).

The SEM images of the optimized sample surface deposited on bare glass are shown in Fig. 6. The material is polycrystalline, comprised of grains $\sim 310 \mathrm{~nm}$ in size. The SEM images of a sample surface of a film grown on a seed layer are also shown in Fig.5 for comparison. The films have a comparable thickness, 1800 and $1920 \mathrm{~nm}$ respectively for the film on bare glass and the seeded sample. These images show that the nucleation is significantly affected by the seed layer, with the surface morphology of the nanoparticle seed layer retained to the film surface. Large coalesced grains are present $1.5-2 \mu \mathrm{m}$ in size, which are comprised of smaller grains of 200$290 \mathrm{~nm}$ size. There is a clear increase in surface roughness 
TABLE I

SUMMARY OF THE ELECTRICAL PROPERTIES OF THE BEST SAMPLES, BEFORE AND AFTER THE ANNEALING TREATMENT.

\begin{tabular}{|c|c|c|c|c|c|}
\hline Sample & $\begin{array}{l}\text { Thickness } \\
(\mathbf{n m})\end{array}$ & $\begin{array}{c}\text { Resistivity } \\
\text { Hall Effect } \\
(\Omega \mathrm{cm})\end{array}$ & $\begin{array}{c}\text { Carrier } \\
\text { Concentration } \\
{ }^{2} \\
(/ \mathrm{cm})\end{array}$ & $\begin{array}{l}\text { Mobility } \\
\quad 2 \\
(\mathrm{~cm} / \mathrm{Vs})\end{array}$ & $\operatorname{Rs}(\Omega /)$ \\
\hline AZO & 1800 & $2.31 \times 10^{-2}$ & $-9.03 \times 10^{19}$ & 2.99 & 67.50 \\
\hline AZO annealed $\left(400^{\circ} \mathrm{C} \mathrm{Ar} / \mathrm{H}_{2}\right)$ & 2200 & $9.11 \times 10^{-3}$ & $-1.57 \times 10^{20}$ & 4.37 & 42.20 \\
\hline AZO (plasma) & 2970 & $1.92 \times 10^{-2}$ & $-8.01 \times 10^{1 y}$ & 4.05 & 36.78 \\
\hline AZO (plasma) annealed $\left(500^{\circ} \mathrm{C} \mathrm{Ar}\right)$ & 2662 & $7.69 \times 10^{-3}$ & $-1.35 \times 10^{20}$ & 6.00 & 22.46 \\
\hline AZO seeded & 1920 & $4.64 \times 10^{-2}$ & $-5.89 \times 10^{1 y}$ & 2.28 & 121.43 \\
\hline AZO seeded & 2601 & $2.02 \times 10^{-2}$ & $-7.32 \times 10^{19}$ & 4.22 & 73.48 \\
\hline AZO seeded annealed $\left(500^{\circ} \mathrm{C} \mathrm{Ar}\right)$ & 2675 & $9.66 \times 10^{-3}$ & $-1.02 \times 10^{20}$ & 6.33 & 23.31 \\
\hline
\end{tabular}

visible in the films incorporating a seed layer, which was also evident from the optical transmission spectra in Fig.4.

The electrical properties of the films deposited using the optimum conditions, are given in Table 1 . There is a decrease in the resistivity and an increase in the carrier concentration with thickness and with annealing treatment $\left(\mathrm{Ar} / \mathrm{H}_{2}\right.$ in vacuum, $400^{\circ} \mathrm{C}$ or $\mathrm{Ar}, 500^{\circ} \mathrm{C}$ ). Also, there is increased mobility for the AZO film deposited on the nanoparticle seed layer, compared to the as-deposited films on bare glass for a similar thickness. This is due to the more pronounced crystal growth for the nanoparticle seeded substrates. More analysis and further optimization of the process is required to control the mobility, transmittance and resistivity of the film. However, it has been demonstrated that the nanoparticle seed layer is a useful process in the sprayed AZO process for adjusting the film properties.

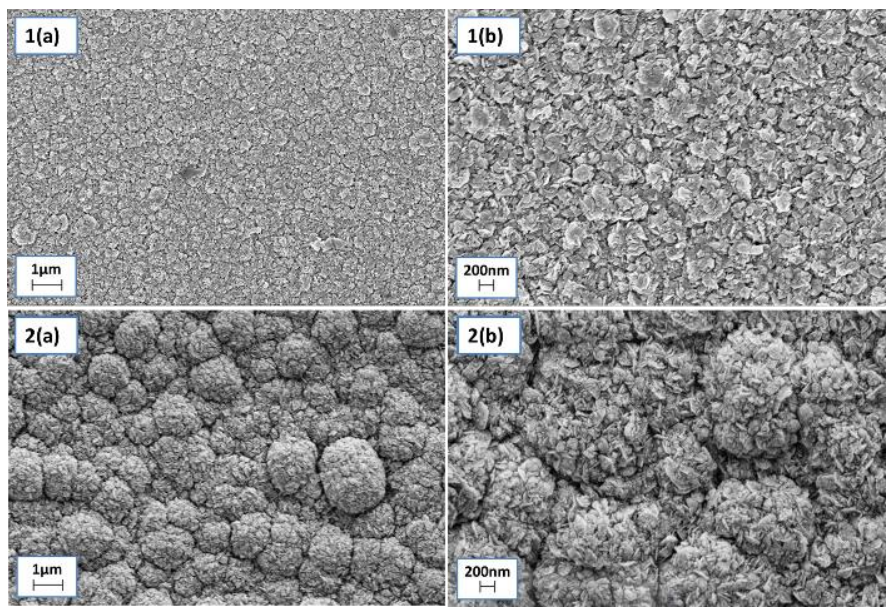

Fig.6. SEM images of two AZO films for comparison. 1(a, b): AZO on bare glass, 2(a, b): AZO on a nanoparticle seed layer.

\section{CONCLUSIONS}

The development of low cost deposition techniques such as spray pyrolysis is challenging, as there are a large number of parameters that can affect the thin film properties. However, by fully optimizing the spray deposition process, AZO layers with good electronic and optical properties have been deposited. AZO films deposited using this low cost atmospheric process have the potential for use as the transparent conducting layer in thin film solar cells.

\section{ACKNOWLEDGEMENT}

The authors are grateful to EPSRC Supergen SuperSolar Hub for funding to support this project and to Innovnano SA for providing the AZO nanoparticles.

\section{REFERENCES}

[1] M. Kaelin, D. Rudmann, and A. N. Tiwari, "Low cost processing of CIGS thin film solar cells," Solar Energy, vol. 77, no. 6, pp. 749-756, Dec. 2004.

[2] K.C. Lai, C.C. Liu, C. Lu, C.H. Yeh, and M.P. Houng, "Characterization of $\mathrm{ZnO}: \mathrm{Ga}$ transparent contact electrodes for microcrystalline silicon thin film solar cells," Solar Energy Materials and Solar Cells, vol. 94, no. 3, pp. 397-401, Mar. 2010.

[3] F. Ruske, C. Jacobs, V. Sittinger, B. Szyszka, and W. Werner, "Large area ZnO:Al films with tailored light scattering properties for photovoltaic applications," Thin Solid Films, vol. 515, no. 24, pp. 8695-8698, Oct. 2007.

[4] A. Čampa, J. Krč, J. Malmström, M. Edoff, F. Smole, and M. Topič, "The potential of textured front $\mathrm{ZnO}$ and flat TCO/metal back contact to improve optical absorption in thin $\mathrm{Cu}(\mathrm{In}, \mathrm{Ga}) \mathrm{Se} 2$ 
solar cells," Thin Solid Films, vol. 515, no. 15, pp. 5968-5972, May 2007.

[5] F. Caillaud, A. Smith, and J. Baumard, "Effect of $\mathrm{pH}$ of the solution on the deposition of zinc oxide films by spray pyrolysis," Journal of the American Ceramic Society vol. 76, no. 4, pp. 998-1002, 1993

[6] W. Kern, "The Evolution of Silicon Wafer Cleaning Technology," Journal of The Electrochemical Society, vol. 137, no. 6 , p. 1887,1990

[7] H. Hagendorfer, K. Lienau, S. Nishiwaki, C. M. Fella, L. Kranz, A. R. Uhl, D. Jaeger, L. Luo, C. Gretener, S. Buecheler, Y. E. Romanyuk, and A. N. Tiwari, "Highly transparent and conductive $\mathrm{ZnO}$ : Al thin films from a low temperature aqueous solution approach.," Advanced materials (Deerfield Beach, Fla.), vol. 26, no. 4, pp. 632-6, Jan. 2014.

[8] N. Neves, R. Barros, E. Antunes, J. Calado, E. Fortunato, R. Martins, and I. Ferreira, "Aluminum doped zinc oxide sputtering targets obtained from nanostructured powders: Processing and application," Journal of the European Ceramic Society, vol. 32, no. 16 , pp. 4381-4391, Dec. 2012.

[9] F. Lisco, a. Abbas, B. Maniscalco, P. M. Kaminski, M. Losurdo, K. Bass, G. Claudio, and J. M. Walls, "Pinhole free thin film CdS deposited by chemical bath using a substrate reactive plasma treatment," Journal of Renewable and Sustainable Energy, vol. 6, no. 1, p. 011202, Jan. 2014.

[10] M. Jin, J. Feng, Z. De-heng, M. Hong-lei, and L. Shu-ying, "Optical and electronic properties of transparent conducting
$\mathrm{ZnO}$ and $\mathrm{ZnO}:$ Al films prepared by evaporating method," vol. 357, pp. 99-102, 1999.

[11] P. Nunes, A. Malik, B. Fernandes, E. Fortunato, P. Vilarinho and R. Martins, "Influence of the doping and annealing atmosphere on zinc oxide thin films deposited by spray pyrolysis," Vacuum, vol. 52, pp. 45-49, 1999.

[12] E. Arca, K. Fleischer, and I. V. Shvets, "Influence of the Precursors and Chemical Composition of the Solution on the Properties of ZnO Thin Films Grown by Spray Pyrolysis," The Journal of Physical Chemistry C, vol. 113, no. 50, pp. 2107421081, Dec. 2009.

[13] A. Mosbah, S. Abed, N. Bouhssira, M. S. Aida, and E. Tomasella, "Preparation of highly textured surface $\mathrm{ZnO}$ thin films," Materials Science and Engineering: B, vol. 129, no. 1-3, pp. 144-149, Apr. 2006.

[14] F. Ruske, C. Jacobs, V. Sittinger, B. Szyszka, and W. Werner, "Large area ZnO:Al films with tailored light scattering properties for photovoltaic applications," Thin Solid Films, vol. 515, no. 24, pp. 8695-8698, Oct. 2007.

[15] R. Elilarassi and G. Chandrasekaran, "Effect of annealing on structural and optical properties of zinc oxide films," Materials Chemistry and Physics, vol. 121, no. 1-2, pp. 378-384, May 2010. 